\title{
Desempenho do Índice de Sustentabilidade Empresarial (ISE) da Bolsa de Valores de São Paulo sob a ótica do Índice de Sharpe
}

\section{Performance of the Organizational Sustainability Index (ISE) of the São Paulo Stock Exchange from the Sharpe Ratio perspective}

\author{
Rodrigo Alves de Melo \\ PPGEN/UFRuralRJ \\ rodrigo.a.melo@hotmail.com \\ João Victor da Paschoa Manhães \\ PPGEN/UFRuralRJ \\ joao.manhaes@sepetibatecon.com.br \\ Marcelo Álvaro da Silva Macedo \\ FACC/UFRJ \\ malvaro.facc.uftj@gmail.com
}

Editor Científico Responsável Prof. Dr. Armindo dos Santos de Sousa Téodosio Professor do Programa de Pós-graduação em Administração - PUC Minas

Submissão: 08/12/2010

Aprovação: 01/09/2011

\section{Resumo}

Este artigo tem como objetivo analisar se o comportamento socioambientalmente responsável é capaz de gerar impactos financeiros para as empresas, ou seja, se é possível capturar financeiramente os benefícios propostos pela teoria dos stakeholders. Assim, esta pesquisa buscou investigar, entre dezembro de 2005 e novembro de 2009, se o retorno ajustado ao risco - mensurado através do Índice de Sharpe - do Índice de Sustentabilidade Empresarial (ISE), que é composto por empresas reconhecidamente comprometidas com a responsabilidade socioambiental, é estatisticamente igual ao retorno ajustado ao risco de outros índices de ações da Bovespa, cujos critérios de seleção não levam necessariamente em consideração a prática da Responsabilidade Socioambiental Corporativa. Para tanto, no cálculo dos IS mensal de cada índice de mercado utilizou-se como taxa livre de risco o CDI. Os resultados mostram que não há diferenças significativas entre os Índices de Sharpe do ISE, do Ibovespa, do IBrX, do IBrX-50 e do IGC no período estudado. Os resultados também sugerem a existência da Hipótese da Eficiência de Mercado (HEM), pois, se um mercado é eficiente, ele não permite que um investidor obtenha retornos acima da média sem incorrer também em riscos maiores, já que todos os ativos estariam com seus preços em equilíbrio.

Palavras-chave: Desempenho. ISE. Índice de Sharpe. 


\begin{abstract}
This article aims to analyze if the socially and environmentally responsible behavior is able to generate financial impacts for companies, ie, if it is possible to capture the financial benefits offered by the stakeholders theory. So, this study sought to investigate, between December 2005 and November 2009, if the risk adjusted returns - measured by the Sharpe Ratio - of the Organizational Sustainability Index (ISE), which consists of companies committed to the social and environmental responsibility, is statistically equal to the risk adjusted returns of other Bovespa stock indexes, whose selection criteria does not necessarily consider the practice of Corporate Social and Environmental Responsibility. For this purpose, in calculating the monthly SR of each market index was used the $\mathrm{CDI}$ as the risk free rate. The results show no significant differences between the Sharpe Ratio of the ISE, Bovespa index, IBrX, IBrX-50 and the IGC during the study period. The results also suggest the existence of the Efficiency Market Hypothesis (EMH), because if a market is efficient it does not allow an investor to obtain above average returns without incurring major risks also, as all assets would be with their prices balanced.
\end{abstract}

Keywords: Performance. ISE. Sharpe Ratio. 


\section{INTRODUÇÃO}

Com a globalização, as empresas passaram a operar e comercializar seus produtos em nível mundial e a diversidade de cultura passa a ter maior valor dentro desse processo. Os países passaram a exigir das organizações um comportamento socioambientalmente responsável, que respeite os direitos humanos, a liberdade e a participação democrática.

Sob essa perspectiva e guiado pela visão de que as empresas devem conduzir seus negócios de forma ética e obedecendo a valores morais rigorosos, surge o conceito de Responsabilidade Socioambiental Corporativa. Esse novo conceito caracteriza organizações baseadas em: preocupação com atitudes éticas e morais; promoção de valores e comportamentos morais; respeito ao meio ambiente e sustentabilidade; e maior envolvimento com a comunidade na qual se insere e contribuição para seu desenvolvimento. (ASHLEY, 2005).

A base dessa teoria propõe que as organizações devam tomar decisões que estejam alinhadas com todos os grupos de interesse ou indivíduos que possam afetar ou serem afetados pelas atividades da empresa, os chamados stakeholders.

A teoria dos stakeholders descreve que a capacidade de uma firma gerar riqueza sustentável no tempo é determinada por suas relações com os diversos públicos de interesse. De acordo com esta teoria, a corporação é definida como uma organização socioeconômica construída para criar riqueza para os diversos constituintes (DIAS; BARROS, 2008).

De acordo com o Instituto Ethos (2010), a cobrança pela responsabilidade socioambiental das empresas por parte da sociedade teve início na Europa nos anos 1970. O país pioneiro nesse processo foi a França, em 1977, com a criação de uma lei que obrigava as empresas com mais de 300 funcionários a divulgar, em balanços, suas ações socioambientais.

No Brasil, as empresas começaram a se sensibilizar em relação à Responsabilidade Socioambiental no início dos anos 1990 e ganhou forte impulso ao longo da década, pela ação de entidades não-governamentais e institutos de pesquisa e pelo engajamento da iniciativa privada nas novas políticas sociais do governo. (INSTITUTO ETHOS DE EMPRESAS E RESPONSABILIDADE SOCIAL, 2010).

Segundo o Instituto Ethos (2010), a resposta ao anseio mundial surgiu com os índices de sustentabilidade empresarial no mercado financeiro. O primeiro deles foi o Dow Jones 
Sustainability Index, lançado em 1999 pela Dow Jones \& Company, empresa americana dedicada a informações sobre negócios. No Brasil, a Bolsa de Valores de São Paulo (Bovespa) lançou em 2005 o Índice de Sustentabilidade Empresarial (ISE), que reflete o retorno de uma carteira composta por ações de empresas reconhecidamente comprometidas com a responsabilidade socioambiental e a sustentabilidade empresarial e atuam como promotoras de boas práticas no meio empresarial brasileiro.

É nessa perspectiva que este trabalho busca se inserir, tendo como problema de pesquisa a seguinte questão: qual o impacto financeiro causado por um comportamento socioambientalmente responsável?

Sendo assim, este artigo tem como objetivo analisar se o comportamento socioambientalmente responsável é capaz de gerar impactos financeiros para as empresas, ou, em outras palavras, se é possível capturar financeiramente os benefícios propostos pela teoria dos stakeholders. Neste trabalho, esta análise será operacionalizada por meio de testes estatísticos, em que se procura verificar se o Índice de Sharpe do ISE é semelhante ao Índice de Sharpe de outros índices de mercado, ou seja, se seu retorno ajustado ao risco é diferenciado dos demais pelo fato de sua carteira teórica ser somente composta por ações de empresas que possuem práticas socialmente responsáveis. 


\section{RESPONSABILIDADE SOCIOAMBIENTAL}

O tema responsabilidade socioambiental ocupa hoje grande espaço na produção acadêmica, na mídia e nos negócios, em que se destaca o debate sobre a ação socioambiental das empresas.

Nesse sentido, já que as organizações têm um papel importante perante a sociedade, elas devem pensar sua atuação, dentro dos princípios da responsabilidade socioambiental, em relação às diferentes sociedades nas quais estão inseridas, cada qual com seu valor ético, moral e cultural.

De acordo com Araújo (2006), a Responsabilidade Socioambiental Empresarial (RSE) é um dos novos fenômenos de mercado que emergiram com a globalização.

Nas palavras de Aliglieri L., Aligleri A. e Krugliankas (2009), a preocupação com posturas socialmente corretas, ambientalmente sustentáveis e economicamente viáveis está cada vez mais presente entre os temas de gestão, e a sustentabilidade pode ser percebida como um dos temas mais debatidos e propagados na gestão. Isso porque, num ambiente em que a informação trafega com grande velocidade nas mais diversas mídias, as externalidades das empresas, sejam positivas ou negativas, tornam-se disponíveis a todos quase em tempo real.

Nesse contexto, melhores condições de trabalho, respeito ao meio ambiente (preservação e reparo dos danos causados ao meio ambiente), redução das desigualdades sociais e raciais, apoio às comunidades locais, dentre outras questões, passaram a fazer parte do repertório organizacional. (DEEGAN; RANKIN, 1997; DIAS; SIQUEIRA, 2006).

Isso se justifica, segundo Moraes (2000) e Stoner e Freeman (1995), pelo fato de as corporações possuírem responsabilidade de agir para o bem da sociedade em que se inserem, obtendo benefícios ao não ignorarem tal fato. Nesse contexto, Mattila (2009) acrescenta que o que trouxe essa maior atenção à responsabilidade socioambiental nos últimos tempos foi um melhor entendimento de seus benefícios potenciais para a competitividade das empresas.

Segundo Daft (1997), a responsabilidade socioambiental pode ser entendida como o ato de empreender ações que melhorem o bem-estar social e vão ao encontro dos interesses da sociedade, bem como da organização. Essa congruência dos objetivos empresariais e socioambientais, nas palavras de Drucker (2001), pode ser justificada pelo fato de que as instituições só podem existir dentro de um ambiente social e são, de fato, órgãos da sociedade. Sendo assim, é difícil a existência de uma organização saudável em uma sociedade que não seja também sã. 
Na síntese das palavras de Melo Neto e Froes (1999), Tenório (2004), Ashley (2005), Parente e Gelman (2006) e Oliveira (2005), pode-se entender a responsabilidade socioambiental como um compromisso da empresa em relação à sociedade. Esta pode ser encarada como uma forma de gestão definida pela relação ética e transparente da empresa com todos os públicos com os quais ela se relaciona, no que tange a sua maneira de agir, de impactar e de se relacionar com seus stakeholders.

A responsabilidade socioambiental das empresas está relacionada à cultura empresarial e nacional, ou seja, está condicionada ao conjunto de mecanismos simbólicos, estruturas cognitivas e valores que dão sentido às práticas, pensamentos e comportamentos das pessoas. Esses valores somados (valores éticos, morais e culturais) influenciam o modo como os princípios de responsabilidade socioambiental corporativa são concebidos nas diversas sociedades. (ASHLEY, 2005).

Segundo o Instituto Ethos de Empresas e Responsabilidade Social (2010), a responsabilidade socioambiental é:

a forma de gestão que se define pela relação ética e transparente da empresa com todos os públicos com os quais ela se relaciona e pelo estabelecimento de metas empresariais que impulsionem $o$ desenvolvimento sustentável da sociedade, preservando recursos ambientais e culturais para as gerações futuras, respeitando a diversidade e promovendo a redução das desigualdades sociais.

Já de acordo com Bateman e Snell (1998), a responsabilidade socioambiental é "a extensão do papel empresarial além de seus objetivos econômicos". Ainda segundo os autores, ações socialmente responsáveis podem trazer vantagens em longo prazo para as organizações como, por exemplo, uma empresa percebida como socioambientalmente responsável pode melhorar sua imagem e evitar regulamentação desnecessária.

Para Toldo (2002, p. 79), responsabilidade socioambiental é:

o comprometimento permanente dos empresários de adotar um comportamento ético e contribuir para o desenvolvimento econômico, melhorando simultaneamente a qualidade de vida de seus empregados e de suas famílias, da comunidade local e da sociedade como um todo.

Segundo Young (2010), as expectativas dos stakeholders em relação às empresas tendem a aumentar à medida que estes começam a acessar mais informações das empresas e 
sobre sustentabilidade, o que faz com que passem a exigir maior responsabilidade e transparência nas ações empresariais.

Com isso, as empresas passaram a buscar um equilíbrio entre as ações de cunho estritamente econômico com as ações de cunho social e ambiental. Ou seja, as empresas passaram a ter preocupações com ações de benefício socioambiental, mas buscando alcançar um nível mínimo de lucratividade para assegurar a continuidade das operações (mantendo ou aumentando seu nível de competitividade), pois a sociedade não tem nada a ganhar e tudo a perder, se a capacidade da instituição de desempenhar sua tarefa específica for reduzida ou prejudicada. (DRUCKER, 2001).

Nesse sentido, Costanza (1991) ressalta que as empresas passaram a operar num contexto de relação entre as dinâmicas econômica, social e ambiental, em que se tem a constante busca por eficiência econômica, justiça social e qualidade ambiental. Isso porque, de acordo com Souza, Andrade e Cândido, (2008), não existe mais espaço para que o capital econômico consiga se acumular e reproduzir sustentavelmente onde não exista um conjunto de outras dimensões, baseadas, principalmente, em aspectos sociais e ambientais.

Segundo Lima, Gómez e Catillo (2008), a abrangência dessas três perspectivas: econômica, social e ambiental, forma o que Sachs (2007) denominou de ecossocioeconomia. Já de acordo com Vellani e Ribeiro (2006), essas dimensões se referem ao chamado Tripple Bottom Line (TBL) da sustentabilidade.

Macedo e Cípola (2009) ressaltam que as discussões passaram a se centrar na questão do desenvolvimento sustentável, baseado no tripé econômico, social e ambiental, em que o reconhecimento dos problemas econômicos, sociais e ambientais não tratados foi o terreno fértil para a inserção da discussão sobre sustentabilidade.

Em resumo, Ruthes e Nascimento (2006) destacam que o desenvolvimento sustentável, então, se refere à sustentabilidade econômica, social e ambiental, sendo, portanto, uma integração dessas perspectivas em uma única.

Macedo (2009) comenta que a amplitude e a importância do conceito de desenvolvimento sustentável fazem com que se torne necessário o desenvolvimento de sistemas de informação para apoiar o processo de gestão deste, por meio da elaboração de metodologias para mensuração do nível de sustentabilidade. Assim sendo, torna-se necessária a criação de um ferramental que auxilie no acompanhamento e na avaliação dos avanços e/ou retrocessos do desenvolvimento sustentável, por meio da utilização de um conjunto de 
indicadores relacionados à sustentabilidade, tornando-a mensurável e assim mais facilmente operacionalizada.

Uma das tentativas de construção desse instrumento, sob a perspectiva socioambiental, é o Balanço Social, que, segundo Tinoco $(1984 ;$ 2001), é um instrumento de gestão e de informação, que espelha a situação socioambiental na empresa.

De acordo com Tenório (2004), o Balanço Social apresenta informações a respeito dos impactos que as atividades empresariais exercem sobre os trabalhadores, a sociedade, a comunidade e o meio ambiente, procurando justificar explicitamente a existência da empresa, por meio de provas de seu custo-benefício. Isso é positivo, porque agrega valor à economia e à sociedade, porque respeita os direitos humanos de seus colaboradores e, ainda, porque desenvolve todo o seu processo operacional sem agredir o meio ambiente.

Tenório (2004) destaca, ainda, os benefícios proporcionados pela implantação do balanço social: a identificação do grau de comprometimento social da empresa com a sociedade, os empregados e o meio ambiente; a evidenciação, por meio de indicadores, das contribuições à qualidade de vida na sociedade; a avaliação da administração por meio de resultados sociais e não somente financeiros. Porém alguns autores, entre eles Deegan, Rankin e Tobin (2002) e Jones, Comfort e Hillier (2005), apontam para problemas, como a ausência de evidenciação dos aspectos negativos e a existência de uma diferença substancial na natureza e nos conteúdos dos diversos modelos de relatórios sociais.

Neste ponto, cabe ressaltar que existe certa controvérsia sobre o desenvolvimento de ações de responsabilidade socioambiental por parte das organizações, tendo como base o conflito existente nas teorias dos stockholders e dos stakeholders.

Segundo Friedman (1970), maior representante do pensamento da teoria dos stockholders (ou shareholders) e um dos principais críticos das ações empresariais voltadas para a responsabilidade socioambiental, a única responsabilidade de uma organização é a geração de lucros e riqueza para seus acionistas, Quaisquer ações diferentes dessa podem colocar em risco a sobrevivência da empresa, além de dar origem a um problema de agência entre os acionistas e os gestores. Nessa linha, tem-se uma relação negativa entre responsabilidade socioambiental e performance financeira.

Já na teoria dos stakeholders, de acordo com Freeman (1994), existe a necessidade de a empresa dar atenção a uma multiplicidade de grupos relacionados com ela própria. Essa atenção gera uma relação positiva entre responsabilidade socioambiental e performance financeira, não existindo qualquer desvio na função da empresa. 
Dessa visão surge a necessidade de que as organizações precisam levar em consideração os retornos que otimizem não somente os ganhos para os acionistas mas também para as demais partes interessadas, sendo importante definir, medir e monitorar os interesses desta, além de associá-los aos indicadores de desempenho da empresa.

Tendo como base essas duas teorias e o ambiente de exigência da sociedade por comportamentos socioambientalmente responsáveis por parte das organizações, segundo Donnely Jr., Gibson e Ivancevich (1995), pode-se dizer que existem diferentes abordagens de responsabilidade socioambiental que indicam interpretações e caminhos alternativos para sua operacionalização.

A primeira está ligada à visão de responsabilidade socioambiental como obrigação, em que a ação socioambientalmente responsável está associada à legalidade desta. Nessa condição, a responsabilidade socioambiental está fortemente vinculada ao pensamento de Friedman (1984), com base na teoria dos stockholders, na qual uma organização só possui uma única responsabilidade: usar seus recursos e dedicar-se a atividades destinadas a aumentar seus lucros até onde permaneça dentro das regras.

A segunda interpretação é a reação socioambiental, em que a sociedade direcionaria demandas às empresas, que reagiriam atendendo a seus "apelos socioambientais". Por fim, a última seria a denominada sensibilidade socioambiental, em que as empresas se antecipariam a estas adotando uma postura proativa.

Percebe-se, então, que a operacionalização da responsabilidade socioambiental pode ir desde a ampla perspectiva da sensibilidade até a limitada abordagem defendida pela obrigação, cristalizada na visão crítica de Friedman (1984).

Para Oliveira (2008) e Siqueira (2009), o confronto entre as teorias dos stakeholders e dos stockholders mostra que a diferença básica entre as duas é uma questão de amplitude de visão, no que se refere às possibilidades de as empresas terem benefícios financeiros com seus investimentos socioambientais. Isso porque, segundo os autores, a visão "friedmaniana" é muito estreita, pois tem uma visão de sistema fechado de empresa, voltado para racionalização de operações, maximização de eficiência e redução de custo, enquanto a teoria dos slakeholders tem uma visão de empresa como sistema aberto que afeta e é afetado pelo meio que o cerca.

Nesse sentido, Paula, Pinto e Paiva (2002) afirmam que tanto o comprometimento ético com a sociedade quanto o discurso ideológico que viabiliza sua permanência no mercado estão presentes nas políticas e nas práticas de gestão socioambientalmente 
responsáveis, desenvolvidas pelas empresas. Estas poderiam ser vistas como pontos extremos dentro de um continuum, em que as decisões empresariais seriam uma combinação de ambas, ora pendendo para uma extremidade, ora pendendo para outra.

O contexto desse discurso ideológico deve ser destacado, pois, de acordo com Brown e Deegan (1998) e Deegan, Rankin e Tobin (2002), não se pode deixar de ressaltar o que mostra a Teoria da Legitimidade, no que diz respeito à motivação e aos incentivos que as empresas têm para fazer disclosure socioambiental.

De acordo com Macedo et al. (2009), o que se espera é que, ao adicionarem a suas competências básicas a conduta ética e socioambientalmente responsável, as empresas conquistem o respeito das pessoas e das comunidades atingidas por suas atividades, o engajamento de seus colaboradores e a preferência dos consumidores. Com isso, é esperado que investidores considerem que essas empresas gerariam valor para o acionista no longo prazo, tendo em vista que estão mais preparadas para enfrentar riscos econômicos, sociais e ambientais.

Segundo Oliveira (2008), a responsabilidade socioambiental surge como um diferencial competitivo: reduzindo custos, criando um clima de maior satisfação envolvendo empregados e parceiros, melhorando a imagem da empresa e agregando valor para os acionistas e o mercado financeiro. É neste último aspecto que o presente estudo tem seu foco de análise sobre os impactos da responsabilidade socioambiental. 


\section{RETORNO AJUSTADO AO RISCO}

Até o desenvolvimento da Teoria de Portfólios, inicialmente proposta por Markowitz em 1952, o desempenho dos ativos era mensurado apenas pela rentabilidade obtida pela carteira no período avaliado. A partir de então, percebeu-se a importância da avaliação do risco associado aos investimentos, de modo que a maximização dos retornos deixou de ser priorizada e passou-se a avaliar o retorno ajustado ao risco assumido para obtê-lo.

Segundo Duarte Júnior (2005), o retorno pode ser definido como ganho ou perda, decorrente de um investimento para um intervalo de tempo fixado, e o risco é qualquer medida numérica da incerteza, a qual está sempre presente nos investimentos.

Segundo Securato (1993 apud ODA, 2007), o conceito de risco está associado à incerteza ou variabilidade e pode ser definido por meio do desvio-padrão da distribuição de probabilidades de uma determinada variável aleatória. Quanto maior a volatilidade dos retornos de um ativo, maior será seu desvio-padrão e maior será o risco associado.

Sharpe (1966) desenvolveu um índice que avalia o retorno de um portfólio ajustado ao seu risco. O Índice de Sharpe (IS) é calculado dividindo-se o prêmio de risco obtido pelo portfólio por seu desvio-padrão (HAUGEN, 1997). Ou seja, ele mede o retorno obtido pelo índice de mercado $\left(\bar{R}_{i}\right)$ acima da taxa livre de risco $\left(R_{f}\right)$ por unidade de risco total assumido, ou seja, a volatilidade dos retornos do índice $\left(\sigma_{i}\right)$ :

$$
I S=\frac{\bar{R}_{i}-R_{f}}{\sigma_{i}}
$$

Sua simplicidade de simulação fez com que ele se tornasse um índice muito utilizado no país.

Diante do exposto, operacionaliza-se a problemática do estudo da seguinte maneira: o retorno ajustado ao risco do Índice de Sustentabilidade Empresarial (ISE) é igual ao retorno ajustado ao risco dos demais índices de ações da Bovespa? 


\section{4 ÍNDICE DE SUSTENTABILIDADE EMPRESARIAL (ISE) E OS DEMAIS ÍNDICES DA BOVESPA}

Nos últimos anos observa-se uma tendência mundial de os investidores procurarem aplicar seus recursos em empresas socioambientalmente responsáveis, sustentáveis e rentáveis. Os Investimentos Socioambientalmente Responsáveis (do inglês Socially Responsible Investments - SRI) consideram que "empresas sustentáveis geram valor para o acionista no longo prazo, pois estão mais preparadas para enfrentar riscos econômicos, sociais e ambientais" (BM\&FBOVESPA, 2010a). Ao longo do tempo essa demanda veio se fortalecendo e hoje é amplamente atendida por vários instrumentos financeiros no mercado internacional. (BM\&FBOVESPA, 2010a).

No caso brasileiro, os SRI já tiveram início e há expectativa de que eles cresçam e se consolidem rapidamente. Com o objetivo de criar um referencial para os investimentos socioambientalmente responsáveis, a Bovespa, em conjunto com várias instituições ABRAPP, ANBID, APIMEC, IBGC, IFC, Instituto ETHOS e Ministério do Meio Ambiente uniram esforços e criaram o ISE - Índice de Sustentabilidade Empresarial (BM\&FBOVESPA, 2010a).

O ISE tem por objetivo refletir o retorno de uma carteira composta por ações de empresas com reconhecido comprometimento com a responsabilidade socioambiental e a sustentabilidade empresarial e também atuar como promotor das boas práticas no meio empresarial brasileiro.

De acordo com Monzoni, Biderman e Brito , "o principal objetivo do índice é criar um ambiente de investimento compatível com as demandas de desenvolvimento sustentável da sociedade contemporânea e estimular a responsabilidade ética das corporações." (MONZONI; BIDERMAN; BRITO, 2006, p. 6).

De maneira específica, o ISE mede o retorno total de uma carteira teórica composta por ações de empresas com reconhecido comprometimento com a responsabilidade socioambiental e a sustentabilidade empresarial (no máximo 40). Tais ações são selecionadas entre as mais negociadas na Bovespa em termos de liquide'z e são ponderadas na carteira pelo valor de mercado das ações disponíveis à negociação. (BM\&FBOVESPA, 2010a).

Para Monzoni, Biderman e Brito (2006), sob o aspecto da sustentabilidade corporativa, o ISE pode ser utilizado como ferramenta para análise comparativa do desempenho das empresas listadas na Bovespa, pois é baseada em eficiência econômica, equilíbrio ambiental, 
justiça social e governança corporativa. Ainda segundo os autores, o ISE poderá instruir os investidores preocupados com questões éticas a distinguirem empresas e grupos empresariais comprometidos com a sustentabilidade empresarial e poder diferenciá-los em termos de qualidade, nível de compromisso, transparência, desempenho, dentre outros fatores.

Segundo Figueiredo, Abreu e Las Casas (2009), o ISE é o primeiro indicador financeiro de sustentabilidade criado no Brasil e considera os conceitos internacionais de Triple Bottom Line, que integra a avaliação das dimensões econômico-financeiras, sociais e ambientais das organizações.

De acordo com a BM\&FBovespa (2010a), o ISE tem como missão: ser composto por empresas que se destacam em responsabilidade socioambiental, com sustentabilidade no longo prazo; ser um referencial do desempenho das ações desse tipo de empresa; ser percebido como tal pelo mercado (credibilidade); ser replicável; estimular boas práticas por parte das demais empresas.

O questionário apresenta a seguinte estrutura de avaliação (FIG. 1):

\section{Figura 1: Estrutura de avaliação do questionário}
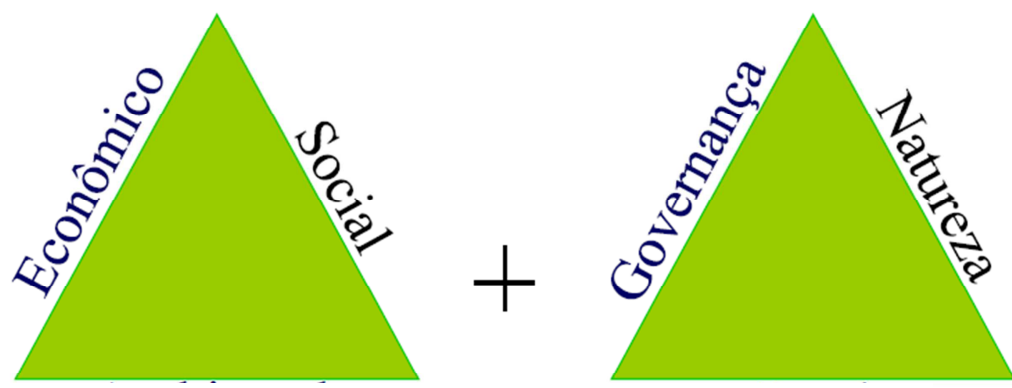

Fonte: BM\&FBovespa (2010a)

Para a BM\&FBovespa (2010a), a empresa participante do ISE passa a ser:

a) reconhecida pelo mercado como empresa que atua com responsabilidade socioambiental corporativa;

b) reconhecida como empresa com sustentabilidade no longo prazo;

c) reconhecida como empresa preocupada com o impacto ambiental de suas atividades.

Em resumo: o ISE é um "selo de qualidade". Segundo Monzoni, Biderman e Brito (2006), a criação do ISE é um importante exemplo dado pelo Brasil perante o resto do mundo e para os mercados de bolsas de valores, o que credita significância tanto no contexto nacional quanto no internacional. 
Outros índices de mercado criados pela Bovespa também têm a finalidade de verificar a rentabilidade de uma carteira teórica composta pelas empresas que atendam às condicionantes do índice em questão, mas não necessariamente possuam boas práticas de sustentabilidade empresarial e responsabilidade socioambiental. Entre eles estão o Ibovespa, o IBrX, o IBrX-50 e o IGC.

O Índice Bovespa (Ibovespa) é considerado o mais importante índice do mercado de ações brasileiro, devido a sua representatividade e sua tradição, uma vez que as ações integrantes do índice respondem por mais de $80 \%$ do número de negócios e do volume financeiro verificados no mercado à vista. O Ibovespa manteve a integridade de sua série histórica e não sofreu modificações metodológicas desde sua implementação em 1968. (BM\&FBOVESPA, 2010b).

O Índice Brasil (IBrX) é um índice composto por 100 ações selecionadas entre as mais negociadas na Bovespa, em termos de número de negócios e volume financeiro. Essas ações são ponderadas na carteira do índice por seu respectivo número de ações disponíveis à negociação no mercado. (BM\&FBOVESPA, 2010b).

O Índice Brasil 50 (IBrX-50) apresenta as mesmas características do IBrX, porém é composto por uma carteira teórica das 50 ações com maior liquidez negociadas na Bovespa, ponderadas na carteira pelo valor de mercado das ações disponíveis à negociação. (BM\&FBOVESPA, 2010b).

O Índice de Ações com Governança Corporativa Diferenciada (IGC) tem por objetivo medir o desempenho de uma carteira teórica composta por ações de empresas que apresentem bons níveis de governança corporativa, as quais devem ser negociadas no Novo Mercado ou estar classificadas nos Níveis 1 ou 2 da Bovespa. (BM\&FBOVESPA, 2010b).

Há ainda diversos outros índices listados na Bovespa, sendo a maioria deles índices setoriais, compostos por ações de empresas de determinado segmento do mercado, como o ITEL (Índice Setorial de Telecomunicações), o IEE (Índice de Energia Elétrica), o IMOB (Índice Imobiliário), o IFNC (Índice Financeiro), entre tantos outros, os quais não serão abordados neste trabalho por não refletirem o mercado como um todo, mas apenas um dos segmentos dele. 


\section{DESEMPENHO FINANCEIRO E RESPONSABILIDADE SOCIOAMBIENTAL}

Diversos estudos na literatura buscam inferir uma relação entre responsabilidade socioambiental e o desempenho financeiro das empresas. Como visto anteriormente, alguns autores defendem que a função econômica é a principal fonte de sustentabilidade das organizações e entendem que os investimentos sociais e ambientais acarretam aumento dos custos e consequente redução dos lucros dos acionistas. É a chamada teoria dos stockholders ou teoria dos shareholders. (MACHADO R.; MACHADO V.; CORRAR, 2009).

Outros pesquisadores acreditam que a função econômica é apenas um dos componentes da sustentabilidade e que outros agentes também precisam ter suas necessidades atendidas, caso contrário a sustentabilidade em longo prazo não existirá. Ou seja, a teoria dos stakeholders sugere que a capacidade de a organização gerar riqueza sustentável ao longo do tempo depende não somente da maximização da riqueza dos acionistas mas também das relações que a empresa desenvolve com os diversos públicos de interesse, como os investidores, os fornecedores, os colaboradores e a sociedade. (DIAS; BARROS, 2008).

Há ainda autores que defendem que inexiste relação entre o desempenho socioambiental e financeiro. Segundo McWilliams e Siegel (2001), os investimentos socioambientalmente responsáveis estão submetidos à lei da oferta e da demanda e são mantidos em equilíbrio com o objetivo principal da organização, a maximização do lucro.

Porém, independentemente da existência ou não de uma relação entre desempenho socioambiental e financeiro, a Hipótese da Eficiência de Mercado (HEM) salienta que não é possível vencer o mercado a longo prazo (MACHADO R.; MACHADO V.; CORRAR, 2009). A HEM, proposta inicialmente por Fama (1970), baseia-se na premissa de que os preços dos títulos refletem instantaneamente todas as informações relevantes disponíveis no mercado, desde que não haja custos transacionais, que todas as informações estejam disponíveis sem custos para todos os participantes do mercado e que tais participantes tomem decisões racionais.

Para Malkiel (2003), se um mercado é eficiente, ele não permite que um investidor obtenha retornos acima da média sem incorrer também a riscos maiores, pois nenhum investidor seria capaz de identificar ativos com preços em desequilíbrio. Segundo o autor, evidências da incapacidade dos gestores de fundos de investimento em vencer o mercado como um todo sugerem a existência da Hipótese da Eficiência de Mercado. (MACHADO R.; MACHADO V.; CORRAR, 2009). 
Diversos estudos na literatura compararam índices de mercado entre si com a intenção de se validar a HEM. Alguns desses trabalhos avaliaram se o ISE possuía uma rentabilidade diferenciada dos demais índices do mercado acionário brasileiro por esse ser composto somente por empresas que apresentam práticas socioambientalmente responsáveis, as quais, segundo a teoria dos stakeholders, possuiriam vantagens estratégicas sobre as demais. (REZENDE et al., 2007).

Porém tais estudos avaliaram a performance dos índices de mercado somente a partir de suas rentabilidades nominais. Machado R., Machado V. e Corrar (2009) compararam os retornos nominais médios do ISE com os dos demais índices da Bovespa, entre dezembro de 2005 e novembro de 2007, aplicando o teste não-paramétrico de Kruskal-Wallis às observações e concluíram que o Índice de Sustentabilidade Empresarial não possui melhor retorno que outros índices de ações.

Rezende et al. (2007) também compararam o ISE com o Ibovespa, com o IBrX e com o IGC, utilizando-se de seus retornos nominais mensais de dezembro de 2005 a março de 2007. Os autores aplicaram o teste $t$ de student de duas amostras para médias e concluíram que, no nível de significância de 5\%, o Índice de Sustentabilidade Empresarial possui retorno semelhante aos outros índices de ações.

Esses trabalhos, portanto, compararam tão-somente as rentabilidades dos índices, e, em momento algum, houve uma abordagem dos retornos destes, ajustados a seus respectivos riscos.

Outros estudos também já analisaram esse problema sob a perspectiva de análise de carteiras de investimento socioambientalmente responsável (ISR). Campos e Lemme (2008), em seu estudo, chegaram à conclusão de que inexistem diferenças estatisticamente significativas entre os índices e carteiras ISR e seus benchmarks, no tocante às variáveis risco e retorno. Em outro estudo, Rezende e Santos (2006) concluíram que os ISR brasileiros não possuem melhor rentabilidade que outros fundos de ações de outras empresas constantes do IBOVESPA.

Já outros estudos mostraram o impacto das ações de responsabilidade socioambiental sobre o desempenho financeiro das empresas. Abreu, Soares e Castro Júnior (2006), em seu trabalho, concluíram que a conduta socioambiental é relevante na determinação dos resultados econômico-financeiros da empresa. Na pesquisa de Bernardo et al. (2006) foi identificado que os investimentos em responsabilidade socioambiental, mais especificamente, os de caráter interno e ambiental, criam valor para as empresas e seus acionistas. Klassen e McLaughlin 
(1996) verificaram, na observação de retornos anormais positivos das ações na presença de bons desempenhos socioambientais, que os investidores alteram suas percepções de valor sobre a empresa. Ainda nessa linha, o estudo de Waddock e Graves (1997) mostrou que bom desempenho financeiro permite maior nível de investimento em ações de responsabilidade socioambiental e a melhoria dos indicadores socioambientais das empresas impacta positivamente o desempenho financeiro.

Cabe ressaltar, entretanto, que nem sempre os estudos mostraram haver impacto positivo significativo na relação entre desempenho financeiro e conduta socioambientalmente responsáveis, como se pode observar nos estudos de McWilliams e Siegel (2000), Watson et al. (2004) e Macedo et al. (2007). Simpson e Kohers (2002) ressaltam, porém, que resultados como estes podem estar associados ao fato de que essa relação positiva depende de um horizonte de tempo mais longo do que o normalmente observado nas pesquisas.

É importante ressaltar que possivelmente essas contradições mostram que a construção de vantagens competitivas seja um processo em evolução, decorrente do desenvolvimento de maior consciência socioambiental e de instrumentos que melhor evidenciem à sociedade o perfil socioambiental das organizações. Tal consideração justifica a contínua realização de pesquisas para fins de monitoramento dessa evolução. 


\section{METODOLOGIA}

\subsection{Objetivo do estudo e formulação da hipótese}

Como visto anteriormente, a base de discussão empírica do estudo é construída a partir de uma análise, por meio de testes estatísticos, em que se procura verificar se o retorno ajustado ao risco (Índice de Sharpe) do ISE é semelhante ao de outros índices de mercado, já que a carteira teórica do ISE é composta somente por ações de empresas que possuem práticas socioambientalmente responsáveis.

Assim, com base nesta discussão, surge a hipótese nula:

$\mathrm{H}_{0}$ : O Índice de Sharpe do Índice de Sustentabilidade Empresarial (ISE) é igual ao Índice de Sharpe dos demais índices de mercado da Bovespa.

\subsection{Coleta e tratamento dos dados}

As cotações de fechamento do Índice de Sustentabilidade Empresarial (ISE), do Índice Bovespa (Ibovespa), do Índice Brasil (IBrX), do Índice Brasil 50 (IBrX-50) e do Índice de Ações com Governança Corporativa Diferenciada (IGC) foram obtidas no banco de dados fornecido pela Economática. Tais índices foram escolhidos para serem comparados com o ISE por possuírem critérios de seleção que não levam necessariamente em consideração a prática de políticas socioambientalmente responsáveis.

O período estudado compreende quatro anos de observações, iniciando-se em dezembro de 2005, data de início da operação do ISE, e estendendo-se até novembro de 2009. A exemplo de Machado R., Machado V. e Corrar (2009), os retornos diários dos índices foram calculados pelo regime de capitalização contínua, a partir da equação logarítmica abaixo:

$$
R_{i, t}=\frac{\ln P_{i, t}}{\ln P_{i, t-1}}
$$

Onde:

$R_{i, l}$ é o retorno do índice de mercado $i$ na data $t$;

$P_{i, t}$ é o valor de fechamento do índice de mercado $i$ na data $t$; 
$P_{i, t-1}$ é o valor de fechamento do índice de mercado $i$ da data $t-1$.

Para a realização de testes paramétricos, é necessário que as amostras sigam uma distribuição normal. O cálculo dos retornos pelo regime de capitalização contínua tende a aproximar a distribuição de frequência dos retornos calculados do logarítmico da curva normal, e, apesar de não garantir a normalidade dos dados, a simetria da curva garante uma maior aproximação da normal. (MACHADO R.; MACHADO V.; CORRAR, 2009).

A partir dos retornos diários dos índices, e utilizando-se como taxa livre de risco o CDI, foi possível calcular o Índice de Sharpe (IS) mensal de cada índice aplicando-se a equação 1. Vale ressaltar que, segundo Oda (2007), o CDI pode ser utilizado como taxa livre de risco, pois, além de representar um ativo com baixíssimo risco de crédito, corresponde a uma taxa na qual os fundos conseguem aplicar, além de possuir contratos futuros e opções listados em mercados organizados, facilitando o processo de replicação. 


\section{ANÁLISE DOS DADOS}

\subsection{Estatísticas Descritivas e Teste de Normalidade para as amostras}

A Tabela 1 apresenta as estatísticas descritivas dos $I S$ dos índices de mercado estudados. O IBrX apresentou o maior IS observado em todo o período avaliado, bem como a maior média, enquanto o menor $I S$ observado foi do IGC. No que diz respeito à volatilidade, mensurada pelo desvio-padrão, percebe-se que o Ibovespa é o índice de menor variabilidade, enquanto o IGC é o de maior risco.

\section{Tabela 1 - Estatísticas descritivas do IS dos índices de mercado}

\begin{tabular}{lcccc}
\hline \multicolumn{1}{c}{ Indice } & Média & Desvio padrão & Mínimo & Máximo \\
\hline ISE & 0,051 & 0,194 & $-0,312$ & 0,493 \\
Ibovespa & 0,059 & 0,184 & $-0,316$ & 0,450 \\
IBrX & $\mathbf{0 , 0 6 1}$ & 0,193 & $-0,301$ & $\mathbf{0 , 5 6 0}$ \\
IBrX50 & 0,057 & 0,190 & $-0,302$ & 0,553 \\
IGC & 0,056 & 0,203 & $\mathbf{- 0 , 4 0 6}$ & 0,519 \\
\hline
\end{tabular}

Fonte: Elaborado pelo autor do artigo.

Para a aplicação de testes paramétricos é necessário que as observações da variável em estudo apresentem uma distribuição normal. Para tal, foram realizados os testes de normalidade de Shapiro-Wilk, de Anderson-Darling, de Lilliefors e de Jarque-Bera, cujos resultados são apresentados na Tabela 2. Todos os testes acusaram que os $I S$ dos índices estudados apresentam distribuições normais, uma vez que os p-valores foram maiores que o nível de significância $(\alpha)$ de $5 \%$.

Tabela 2 - Testes de normalidade para as amostras

\begin{tabular}{lcccc}
\hline Índice & Shapiro-Wilk & Anderson-Darling & Lilliefors & Jarque-Bera \\
\hline ISE & 0,4682 & 0,3916 & 0,4769 & 0,4435 \\
Ibovespa & 0,5100 & 0,3055 & 0,2353 & 0,4209 \\
IBrX & 0,6248 & 0,5205 & 0,6443 & 0,5595 \\
IBrX-50 & 0,7340 & 0,7110 & 0,9011 & 0,6030 \\
IGC & 0,6260 & 0,2983 & 0,0801 & 0,6058 \\
\hline
\end{tabular}

Fonte: Elaborado pelo autor do artigo.

Pode-se concluir, portanto, que, em nível de significância de 5\%, os Índices de Sharpe mensais do ISE, do Ibovespa, do IBrX, do IBrX-50 c do IGC, no período de dezcmbro de 2005 a novembro de 2009, apresentaram uma distribuição normal. 


\subsection{Teste de hipótese $t$ de student: duas amostras para médias}

Para Stevenson (1986, p. 223), o teste $t$ de student de duas amostras para médias “consiste em verificar se uma estatística amostral observada pode razoavelmente provir de uma população com o parâmetro alegado".

Com o intuito de se verificar se a média do Índice de Sharpe do ISE é diferente das médias dos $I S$ dos demais índices, o teste $t$ de student foi aplicado em quatro hipóteses, todas em nível de significância de 5\%.

O primeiro teste tem como hipótese nula que a média dos Índices de Sharpe do ISE $\left(\mu_{I S E}\right)$ é igual à média dos Índices de Sharpe do Ibovespa $\left(\mu_{I B O V}\right)$ :

$$
\begin{aligned}
& H_{0}: \mu_{I S E}=\mu_{I B O V} \\
& H_{1}: \mu_{I S E} \neq \mu_{I B O V}
\end{aligned}
$$

O resultado do teste é apresentado na Tabela 3.

Tabela 3 - Teste de hipótese $t$ para as médias do IS do ISE e do Ibovespa

\begin{tabular}{lr}
\hline$\mu_{I S E}$ & 0,051 \\
$\mu_{I B O V}$ & 0,059 \\
Diferença & $-0,008$ \\
$t$ & $-0,845$ \\
\hline p-valor (bilateral) & 0,402 \\
\hline
\end{tabular}

Fonte: Elaborado pelo autor do artigo.

O p-valor bilateral é igual a 0,402, maior que o nível de significância $\alpha$ igual a 0,05. Não se rejeita, portanto, $H_{0}$, ou seja, a média dos Índices de Sharpe do ISE não é estatisticamente diferente da média dos Índices de Sharpe do Ibovespa.

O segundo teste de hipótese compara a média dos Índices de Sharpe do ISE $\left(\mu_{I S E}\right)$ com a média dos Índices de Sharpe do $\operatorname{IBrX}\left(\mu_{I B r X}\right)$ e tem como hipóteses nula e alternativa:

$$
\begin{aligned}
& H_{0}: \mu_{I S E}=\mu_{I B r X} \\
& H_{1}: \mu_{I S E} \neq \mu_{I B r X}
\end{aligned}
$$

O resultado do teste está na Tabela 4. 
Tabela 4 - Teste de hipótese $t$ para as médias do IS do ISE e do IBrX

\begin{tabular}{lr}
\hline$\mu_{I S E}$ & 0,051 \\
$\mu_{I B r X}$ & 0,061 \\
Diferença & $-0,010$ \\
$t$ & $-1,127$ \\
\hline p-valor (bilateral) & 0,266 \\
\hline
\end{tabular}

Fonte: Elaborado pelo autor do artigo.

O p-valor bilateral é igual a 0,266 e é maior que o nível de significância $\alpha$ igual a 0,05 . A hipótese nula $H_{0}$ não pode ser rejeitada, ou seja, a média dos Índices de Sharpe do ISE não é estatisticamente diferente da média dos Índices de Sharpe do IBrX.

O terceiro teste tem como hipótese nula que a média dos Índices de Sharpe do ISE $\left(\mu_{I S E}\right)$ é igual à média dos Índices de Sharpe do IBrX-50 $\left(\mu_{I B r X 50}\right)$ :

$$
\begin{aligned}
& H_{0}: \mu_{I S E}=\mu_{I B r X 50} \\
& H_{1}: \mu_{I S E} \neq \mu_{I B r X 50}
\end{aligned}
$$

O resultado do teste é apresentado na Tabela 5.

Tabela 5 - Teste de hipótese $t$ para as médias do IS do ISE e do IBrX-50

\begin{tabular}{lr}
\hline$\mu_{I S E}$ & 0,051 \\
$\mu_{I B r X 50}$ & 0,057 \\
Diferença & $-0,006$ \\
$t$ & $-0,635$ \\
\hline p-valor (bilateral) & 0,528 \\
\hline
\end{tabular}

Fonte: Elaborado pelo autor do artigo.

O p-valor bilateral é igual a 0,528, maior que o nível de significância $\alpha$ igual a 0,05. Não se rejeita, portanto, $H_{0}$, ou seja, a média dos Índices de Sharpe do ISE não é estatisticamente diferente da média dos Índices de Sharpe do IBrX-50.

O quarto teste de hipótese compara a média dos Índices de Sharpe do ISE $\left(\mu_{I S E}\right)$ com a média dos Índices de Sharpe do IGC $\left(\mu_{I G C}\right)$ e tem como hipóteses nula e alternativa:

$$
\begin{aligned}
& H_{0}: \mu_{I S E}=\mu_{I G C} \\
& H_{1}: \mu_{I S E} \neq \mu_{I G C}
\end{aligned}
$$

O resultado do teste está na Tabela 6. 


\section{Tabela 6 - Teste de hipótese $t$ para as médias do IS do ISE e do IGC $\mu_{\text {ISE }} \quad 0,051$

$\mu_{I G C} \quad 0,056$ \\ Diferença $\quad-0,005$

\begin{tabular}{lr}
$t$ & $-0,445$ \\
\hline p-valor (bilateral) & 0,658 \\
\hline
\end{tabular} \\ Fonte: Elaborado pelo autor do artigo.}

O p-valor bilateral é igual a 0,658 e é maior que o nível de significância $\alpha$ igual a 0,05 . A hipótese nula $H_{0}$ não pode ser rejeitada, ou seja, a média dos Índices de Sharpe do ISE não é estatisticamente diferente da média dos Índices de Sharpe do IGC.

A partir dos testes estatísticos realizados, pode-se concluir que a média dos Índices de Sharpe do Índice de Sustentabilidade Empresarial é semelhante às médias dos Índices de Sharpe dos demais índices de ações abordados (Ibovespa, IBrX, IBrX-50 e IGC).

Isso mostra que não foi possível capturar nenhuma diferença estatisticamente significativa em termos de retorno ajustado ao risco, em virtude de comportamento socioambientalmente responsável, já que a carteira do ISE não apresentou retorno ajustado ao risco superior aos demais índices no período analisado.

Sendo assim, esses resultados estão em consonância com aqueles apresentados por Machado R., Machado V. e Corrar (2009) e Rezende et al. (2007) e são compatíveis com os resultados dos estudos de Campos e Lemme (2008) e Rezende e Santos (2006). Cabe ressaltar, porém, que mais do que refutando a teoria dos stakeholders e confirmando os pressupostos da teoria dos stockholders, os resultados parecem confirmar os achados de outros estudos no que diz respeito à Hipótese da Eficiência de Mercado (HEM). Em outras palavras, o mercado pode estar agindo de modo tão eficiente na formação dos preços, que a posteriori não se é capaz de verificar diferenças no retorno ajustado ao risco. 


\section{CONSIDERAÇÕES FINAIS}

Esta pesquisa buscou investigar, entre dezembro de 2005 e novembro de 2009, se o retorno ajustado ao risco - mensurado por meio do Índice de Sharpe - do Índice de Sustentabilidade Empresarial (ISE), o qual é composto por empresas reconhecidamente comprometidas com a responsabilidade socioambiental e a sustentabilidade empresarial, é estatisticamente igual ao retorno ajustado ao risco de outros índices de ações da Bovespa, cujos critérios de seleção não levam necessariamente em consideração a prática da Responsabilidade Socioambiental Corporativa.

Visando alcançar o objetivo proposto, foi verificada primeiramente a normalidade das amostras, nas quais foi aplicado o teste paramétrico $t$ de student, que evidenciou que não há diferenças significativas entre os Índices de Sharpe do Índice de Sustentabilidade Empresarial (ISE), do Índice Bovespa (Ibovespa), do Índice Brasil (IBrX), do Índice Brasil 50 (IBrX-50) e do Índice de Ações com Governança Corporativa Diferenciada (IGC) no período estudado.

Entretanto não se pode garantir, a partir dos resultados apresentados, que os investimentos socioambientalmente responsáveis não apresentam benefícios financeiros para as empresas, mas apenas que, pela medida utilizada e no período sob análise, o retorno ajustado ao risco de investimentos que não adotam essa prática é similar ao de investimentos socioambientalmente responsáveis.

Tal resultado pode ser explicado por uma restrição importante do presente estudo, que é a participação simultânea de várias empresas com grande representatividade no mercado em diversos índices, os quais podem ser influenciados simultaneamente pelo desempenho das ações dessas empresas na bolsa de valores.

O resultado também sugere a existência da Hipótese da Eficiência de Mercado (HEM), pois, se um mercado é eficiente, ele não permite que um investidor obtenha retornos acima da média sem incorrer também a riscos maiores, já que todos os ativos estariam com seus preços em equilíbrio.

Para pesquisas futuras, é sugerida a utilização de outras medidas de retorno ajustado ao risco, bem como a aplicação de outros testes estatísticos. E, futuramente, a disponibilização de novos dados possibilitará a avaliação de um horizonte de tempo mais longo, com um número maior de observações.

Pelo fato de diversas empresas participarem concomitantemente em vários índices, sugere-se para estudos futuros a consideração dessa participação, ou excluindo-se tais 
empresas dos índices, ou criando-se dois grupos de empresas, um composto somente por empresas que se utilizem de boas práticas de responsabilidade socioambiental e sustentabilidade empresarial, e outro composto por empresas semelhantes no segmento e no porte, porém que não levem em consideração tais políticas.

Além disso, sugere-se a utilização de outras medidas de desempenho financeiro, conjugadas com as de mercado, para que se possam minimizar os efeitos da Hipótese da Eficiência de Mercado (HEM), possibilitando-se verificar os benefícios financeiros isolados do comportamento do mercado de capitais. 


\section{Referências}

ABREU, M. C. S.; SOARES, F. A.; CASTRO JÚNIOR, O. V. Efeito da conduta social sobre a performance econômica dentro do modelo ECP Triplo: evidências na indústria têxtil brasileira. In: SIMPÓSIO DE ADMINISTRAÇÃO DA PRODUÇÃO, LOGÍSTICA E OPERAÇÕES INTERNACIONAIS, 9, 2006, São Paulo. Anais do IX SIMPOI. São Paulo: FGV/EAESP, 2006. CD-ROM.

ALIGLERI, L.; ALIGLERI, L. A.; KRUGLIANKAS, I. Gestão Socioambiental: responsabilidade e sustentabilidade do negócio. São Paulo: Atlas, 2009.

ARAÚJO, M. R. M. Exclusão social e responsabilidade social empresarial. Psicologia em Estudo, v. 11, n. 2, p. 417-426, 2006.

ASHLEY, P. A. Ética e responsabilidade social nos negócios. 2. ed. São Paulo: Saraiva, 2005.

BATEMAN, T. A.; SNELL, S. A. Administração: construindo vantagem competitiva. São Paulo: Atlas, 1998.

BERNARDO, D. C. R.; PESSANHA, G. R. G.; SILVA, S. S.; AVILA, R. C. Investimentos em responsabilidade social empresarial criam valor para as empresas? Um estudo das companhias de capital aberto no Brasil. In: SEMINÁRIOS DE ADMINISTRAÇÃO, 9, 2006, São Paulo. Anais do IX SEMEAD. São Paulo: FEA/USP, 2006. CD-ROM.

BM\&FBOVESPA. Índice de Sustentabilidade Empresarial - ISE. Bolsa de Valores, Mercadorias e Futuros de São Paulo, 2010a. Disponível em:

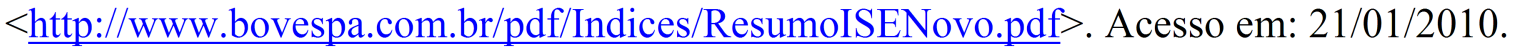

BM\&FBOVESPA. Bolsa de Valores, Mercadorias e Futuros de São Paulo, 2010b. Disponível em $<$ http://www.bovespa.com.br $>$. Acesso em: 20/01/2010.

BROWN, N.; DEEGAN, C. M. The public disclosure of environmental performance information - a dual test of media agenda setting theory and legitimacy theory. Accounting and Business Research, v. 29, n. 1, p. 21-41, 1998.

CAMPOS, F. M.; LEMME, C. F. Incorporação das questões ambientais e sociais nos investimentos no mercado de capitais: análise do desempenho de índices internacionais e fundos de ações nacionais baseados no conceito de investimento socialmente responsável. In: ENCONTRO DA ASSOCIAÇÃO NACIONAL DE PÓS-GRADUAÇÃO E PESQUISA EM ADMINISTRAÇÃO, 32, 2008, Rio de Janeiro. Anais do XXXII ENANPAD. Rio de Janeiro: ANPAD, 2008. CD-ROM.

COSTANZA, R. Ecological Economics: the science and management of sustainability. New York: Columbia Press, 1991.

DAFT, R. L. Management. Fort Worth: Dryden Press, 1997. 
DEEGAN, C.; RANKIN, M. The materiality of environmental information to users of annual reports. Accounting, Auditing \& Accountability Journal, v. 10, n. 4, p. 562-583, 1997.

DEEGAN, C.; RANKIN, M.; TOBIN, J. An Examination of the Corporate Social and Environmental Disclosures of BHP from 1983-1997: A test of legitimacy theory. Accounting, Auditing and Accountability Journal, v. 15, n. 3, p. 312-343, 2002.

DIAS, E. A.; BARROS, L. A. B. C. Índice de Sustentabilidade Empresarial (ISE): o Impacto do Anúncio da Carteira e o Retorno ao Acionista. In: ENCONTRO BRASILEIRO DE FINANÇAS, 8, 2008, Rio de Janeiro. Anais do VIII Encontro Brasileiro de Finanças, 2008. Rio de Janeiro: SBFIN, 2008. CD-ROM.

DIAS, L. N. S.; SIQUEIRA, J. R. M. Análise da evolução qualitativa dos balanços sociais da Petrobras no período de 2000 a 2004. In: CONGRESSO USP DE CONTROLADORIA E CONTABILIDADE, 6, 2006, São Paulo. Anais... São Paulo: FEA/USP, 2006. CD-ROM.

DONNELY Jr., J. H.; GIBSON, J. L.; IVANCEVICH, J. M. Fundamentos de Dirección y Administración de Empresas. México: Irwin, 1995.

DRUCKER, P. A Administração. São Paulo: Nobel, 2001.

DUARTE JÚNIOR, A. M. Gestão de riscos para fundos de investimentos. São Paulo: Prentice Hall, 2005.

FAMA, E. F. Efficient capital markets: A review of theory and empirical work. Journal of Finance, v. 25, n. 2, p. 383-417, 1970.

FIGUEIREDO, G. N.; ABREU, R. L.; LAS CASAS, A. L. Reflexos do Índice de Sustentabilidade Empresarial na imagem das empresas: uma análise do consumidor consciente e do marketing ambiental. Pensamento \& Realidade, v. 25, n. 1, p. 23-23, 2009.

FREEMAN, R. E. The politics of stakeholders theory: some future directions. Business Ethics Quarterly, v. 4, n. 4, p. 409-422, 1994.

FRIEDMAN, M. Capitalismo e Liberdade. São Paulo: Abril Cultural, 1984.

FRIEDMAN, M. The social responsibility of business is increasing its profits. New York Times Magazine, v. 13, n. 9, p. 122-126, set. 1970.

HAUGEN, R. A. Modern Investment Theory. 4. ed. New Jersey: Prentice-Hall, 1997. INSTITUTO ETHOS DE EMPRESAS E RESPONSABILIDADE SOCIAL. Disponível em: $<$ http://www.ethos.org.br $>$. Acesso em: 10/01/2010.

JONES, P.; COMFORT, D.; HILLIER, D. Corporate social responsibility and the UK's top ten retailers. International Journal of Retail e Distribution Management, v. 33, n. 12, p. 882-892, 2005.

KLASSEN, R. D.; MCLAUGHLIN, C. P. The Impact of Environmental Management on Firm Performance. Management Science, v. 42, n. 8, p. 1199-1214, 1996. 
LIMA, M. T. A.; GÓMEZ, C. R. P.; CASTILLO, L. A. G. Cenários de Sustentabilidade: uma ferramenta para inserção do desenvolvimento sustentável na estratégia empresarial. In: SIMPÓSIO DE ADMINISTRAÇÃO DA PRODUÇÃO, LOGÍSTICA E OPERAÇÕES INTERNACIONAIS, 11, 2008, São Paulo. Anais do XI SIMPOI. São Paulo: FGV/EAESP, 2008. CD-ROM.

MACEDO, M. A. S. Análise do nível de sustentabilidade: um estudo apoiado em Análise Envoltória de Dados (DEA). In: SIMPÓSIO DE ADMINISTRAÇÃO DA PRODUÇÃO, LOGÍSTICA E OPERAÇÕES INTERNACIONAIS, 12, 2009, São Paulo. Anais do XII SIMPOI. São Paulo: FGV/EAESP, 2009. CD-ROM.

MACEDO, M. A. S.; CÍPOLA, F. C. Análise do Desempenho Socioambiental no Setor Siderúrgico Brasileiro. Revista de Contabilidade e Organizações (RCO), v. 3, n. 7, p. 58$75,2009$.

MACEDO, M. A. S.; SOUSA, A. C.; SOUSA, A. C. C.; CÍPOLA, F. C. Desempenho de empresas socialmente responsáveis: uma análise por índices contábil-financeiros. Revista Produção Online, Edição Especial, p. 1-22, 2007.

MACEDO, M. A. S.; SOUSA, A. C.; SOUSA, A. C. C.; CÍPOLA, F. C. Análise Comparativa do Desempenho Contábil-Financeiro de Empresas Socialmente Responsáveis. Revista Pensar Contábil, v. 11, n. 43, p. 15-23, 2009.

MACHADO, M. R.; MACHADO, M.A. V.; CORRAR, L. J. Desempenho do Índice de Sustentabilidade Empresarial (ISE) da Bolsa de Valores de São Paulo. Revista Universo Contábil, v. 5, n. 2, p. 24-38, abr./jun., 2009.

MALKIEL, B. G. The efficient markets hypothesis and its critics. Journal of Economic Perspectives, v. 17, n. 1, p. 59-82, 2003.

MATTILA, M. Corporate social responsibility and image in organizations: for the insiders or the outsiders? Social Responsibility Journal, v. 5, n. 4, p. 540-549, 2009.

McWILLIAMS, A.; SIEGEL, D. Corporate social responsibility and financial performance: correlation or misspecification?. Strategic Management Journal, v. 21, n. 5, p. 603-609, 2000 .

MCWILLIAMS, A.; SIEGEL, D. Corporate social responsibility: a theory of the firm perspective. Academy of Management Review, v. 26, n. 1, p. 117-127, 2001.

MELO NETO, F. P.; FROES, C. Q. Responsabilidade Social e Cidadania Empresarial: a administração do terceiro setor. Rio de Janeiro: Qualitymark, 1999.

MONZONI, M.; BIDERMAN, R.; BRITO, R. Finanças sustentáveis e o caso do Índice de Sustentabilidade Empresarial da Bovespa. In: SIMPÓSIO DE ADMINISTRAÇÃO DA PRODUÇÃO LOGÍSTICA E OPERAÇÕES INTERNACIONAIS, 9, 2006, São Paulo. SIMPOI 2006 ANAIS / PROCEEDINGS. Rio de Janeiro: Editora FGV, 2006. 
MORAES, A. M. P. Iniciação ao Estudo da Administração. São Paulo: Makron, 2000. OLIVEIRA, J. A. P. Uma avaliação dos balanços sociais das 500 maiores. RAE Eletrônica, v. 4, n. 1, 2005. Disponível em: <www.rae.com.br/eletronica>. Acesso em: 10 jan. 2007.

OLIVEIRA, J. A. P. Empresas na Sociedade: Sustentabilidade e Responsabilidade Social. Rio de Janeiro: Elsevier, 2008.

ODA, A. L. Desempenho de fundos de ações: análise de persistência de performance dos fundos de ações brasileiros. São Paulo: Saint Paul Editora, 2007.

PARENTE, J.; GELMAN, J. J. Varejo e responsabilidade social, visão estratégica e práticas no Brasil. Porto Alegre: Bookman, 2006.

PAUlA, A. S. A.; PINTO, J. A. R.; PAIVA, K. C. M. Responsabilidade Social: Comprometimento Ético ou Discurso Ideológico?. In: ASSEMBLEIA DO CONSELHO LATINO-AMERICANO DE ESCOLAS DE ADMINISTRAÇÃO, 37, 2002, Porto Alegre. Anais... Porto Alegre, CLADEA, 2002.

REZENDE, I. A. C.; SANTOS, L. S. R. Análise da Rentabilidade e Performance dos Investimentos Socialmente Responsáveis: um estudo empírico no mercado brasileiro. In: ENCONTRO DA ASSOCIAÇÃO NACIONAL DE PÓS-GRADUAÇÃO E PESQUISA EM ADMINISTRAÇÃO, 30, Salvador, 2006. Anais do XXX EnANPAD. Salvador: ANPAD, 2006. CD-ROM.

REZENDE, I. A. C. et al. Um estudo sobre o desempenho financeiro do Índice BOVESPA de Sustentabilidade Empresarial. In: ENCONTRO DA ASSOCIAÇÃO NACIONAL DE PÓSGRADUAÇÃO E PESQUISA EM ADMINISTRAÇÃO, 31, 2007, Rio de Janeiro. Anais... Rio de Janeiro: ANPAD, 2007.

RUTHES, S.; NASCIMENTO, D. E. Desenvolvimento Sustentável e os Arranjos Produtivos Locais. In: SIMPÓSIO DE ADMINISTRAÇÃO DA PRODUÇÃO, LOGÍSTICA E OPERAÇÕES INTERNACIONAIS, 9, 2006, São Paulo. Anais do IX SIMPOI. São Paulo: FGV/EAESP, 2006. CD-ROM.

SACHS, I. Rumo à Ecossocioeconomia: teoria e prática do desenvolvimento. São Paulo: Cortez, 2007.

SHARPE, W. F. Mutual Fund Performance. Journal of Business, v. 39, n. 1, p. 119-138, 1966.

SIMPSON, G.; KOHERS, T. The Link Between Corporate Social and Financial Performance: evidence from the banking industry. Journal of Business Ethics, v. 35, n. 2, p. 97-109, 2002.

SIQUEIRA, J. R. M. Balanço Social: Evidenciação da Responsabilidade Social. In: FERREIRA, A. C. S.; SIQUEIRA, J. R. M.; GOMES, M. Z. (Org.). Contabilidade Ambiental e Relatórios Sociais. São Paulo: Atlas, 2009. 
SOUZA, E. G.; ANDRADE, E. O.; Cândido, G. A. As Influências dos Indicadores de Sustentabilidade nas Políticas e Ações para a Geração do Desenvolvimento Local Sustentável: um estudo exploratório nos municípios produtores de leite no estado da Paraíba. In: SIMPÓSIO DE ADMINISTRAÇÃO DA PRODUÇÃO, LOGÍSTICA E OPERAÇÕES INTERNACIONAIS, 11, 2008, São Paulo. Anais do XI SIMPOI. São Paulo: FGV/EAESP, 2008. CD-ROM.

STEVENSON, W. J. Estatística Aplicada à Administração. São Paulo: Editora Harbra, 1986.

STONER, J. A. F.; FREEMAN, R. E. Administração. Rio de Janeiro, Prentice-Hall, 1995.

TENORIO, F. G. Responsabilidade Social Empresarial: teoria e prática. Rio de Janeiro: FGV, 2004.

TINOCO, J. E. P. Balanço social: uma abordagem sócio-econômica da contabilidade. São Paulo, 1984. Dissertação (Mestrado em Contabilidade) - Universidade de São Paulo, Faculdade de Economia, Administração e Contabilidade, São Paulo.

TINOCO, J. E. P. Balanço social: uma abordagem da transparência e da responsabilidade pública das organizações. São Paulo: Editora Atlas, 2001.

TOLDO, M. Responsabilidade social empresarial. In: ETHOS. Responsabilidade social das empresas: a contribuição das universidades. São Paulo: Petrópolis: Instituto Ethos, 2002. p. 71-102.

YOUNG, R. Gestão da Responsabilidade Social e do Desenvolvimento Sustentável. 2010.

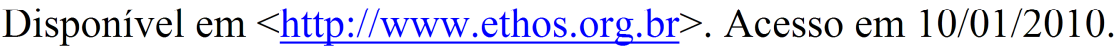

VELLANI, C. L.; RIBEIRO, M. S. A Sustentabilidade e a Contabilidade. In: SIMPÓSIO DE ADMINISTRAÇÃO DA PRODUÇÃO, LOGÍSTICA E OPERAÇÕES INTERNACIONAIS, 9, 2006, São Paulo. Anais... São Paulo: FGV/EAESP, 2006. CD-ROM.

WADDOCK, S. A.; GRAVES, S. B. The Corporate Social Performance-Financial Performance Link. Strategic Management Journal, v. 18, n. 4, p. 303-319, 1997.

WATSON, K.; KLINGENBERG, B.; POLITO, T.; GEUR'TS, T. G. Impact of Environmental Management System Implementation on Financial Performance: a comparison of two corporate strategies. Management of Environmental, v. 15, n. 6, p. 622-628, 2004. 